\title{
Hand-Washing Compliance Rate and the Influencing Factors
}

\author{
Mohammad Gholami Fesharaki ${ }^{1}$; Fatemeh Rahmati-Najarkolaei ${ }^{2, *}$; Zohreh Aghamiri ${ }^{3}$; \\ Masome Mohamadian ${ }^{3}$ \\ ${ }^{1}$ Department of Biostatistics, Faculty of Medical Sciences, Tarbiat Modares University, Tehran, IR Iran \\ ${ }^{2}$ Health Research Center, Baqiyatallah University of Medical Sciences, Tehran, IR Iran \\ ${ }^{3}$ Department of Education \& Research, Najmieh Hospital, Baqiyatallah University of Medical Sciences, Tehran, IR Iran \\ ${ }^{*}$ Corresponding author: Fatemeh Rahmati-Najarkolaei, Health Research Center, Baqiyatallah University of Medical Sciences, Tehran, IR Iran. Tel:+98-2182482469, Fax:+98-2188600062, \\ E-mail: fatemeh_rahmaty@yahoo.com
}

Received: December 31, 2013; Revised: July 31, 2014; Accepted: August 17, 2014

\begin{abstract}
Background: Hand hygiene is closely associated with infection control practices. Improvement of hand hygiene, aimed to minimize nosocomial infection, is a high priority of the World Health Organization(WHO).

Objectives: The current study aimed to explore Hand-Washing Compliance (HWC) rates and influencing factors.

Materials and Methods: Participants of the study were nurses, physicians, secretaries, and hospital care staff of Najmieh Subspecialty Hospital, Tehran, Iran. The Subjects understudy included 127 (90.7\%) females and 13 (9.3\%) males. Simple random sampling was used to select the participants. Both descriptive (frequency and percentage) and inferential statistics (Chi-square test) functions of SPSS version 18 were used to analyze the data.

Results: The overall rate of HWC was 36\%. The minimum and maximum HWC rates were when entering and leaving the wards (17.2\%) and (82.1\%), respectively. According to the results of the study, there was a significant relationship between education, working shift, and HWC rate. No significant relationship was observed between gender, age, experience, and HWC.

Conclusions: According to the findings of the current study, training programs are recommended to be planned with the focus on improving HWC.
\end{abstract}

Keywords:Hand Disinfection; Health Personnel; Behavior

\section{Background}

Hospital-acquired infections (HAIs) refer to infections developed within 48 to 72 hours after patient admission. They can result from unhygienic environments or from patients' normal flora. The infections are often associated with increased morbidity and mortality. Therefore, hygiene-promoting practices are important in order to prevent subsequent complications $(1,2)$. Available literature on the issue suggests that contact, particularly direct contact with patients, is the most important and common transmission channel of the hospital-acquired infections. Among hospital-acquired infection sources, reference can be made to patients, hospital personnel, instruments, and environment (3). Infection-generating micro-organisms are transferred differently. One of the transmission ways is the hands of hospital personnel. Current research findings indicated that a large number of the organisms prevalent among patients can also be found on the hands of hospital personnel (4). Although hand washing is of paramount importance in decreasing and controlling hospital-acquired infections, there are reports of a weak tendency towards performing the simple practice (5-7) Nevertheless, previous studies indicated that overall rate of compliance in hand hygiene is poor $(8,9)$. Improvement of hand hygiene, with the aim of minimizing nosocomial infection, is a high priority of the World Health Organization (WHO) (10). The institutional hand hygiene protocol dictated that hand hygiene had to be applied before and after contact with patients as well as before and after invasive procedures (11).

\section{Objectives}

Considering the significant influence that hand washing can have on preventing and controlling hospitalacquired infections the current study aimed to explore hand washing practice rates and the factors affecting it in a hospital located in Tehran. It matters since reports indicate that implementing training programs and emphasizing on hand-washing practice can significantly decrease hospital-acquired infections $(12,13)$.

\section{Materials and Methods}

This cross-sectional study was conducted on physicians and medical staff of two training hospitals in Tehran province, Iran from 2012 to 2013. The sample size was calculated as 140 subjects, considering $\alpha=5 \%$, statistical power of $90 \%$, and the $\mathrm{P}=15 \%$.

A five-item checklist was checked by trained evaluators

Copyright (C) 2014, Infectious Diseases and Tropical Medicine Research Center; Published by Kowsar. This is an open-access article distributed under the terms of the Creative Commons Attribution-NonCommercial 4.0 International License (http://creativecommons.org/licenses/by-nc/4.0/) which permits copy and redistribute the material just in noncommercial usages, provided the original work is properly cited. 
to inconspicuously watch hand-washing practices. The items of the checklist were related to washing hands when entering the ward, after touching documents, telephones, etc., before and after performing a given procedure, and finally, before leaving the ward. Content validity of the checklist was evaluated based on library studies. Reliability of the checklist was checked using Kuder-Richardson formula $20(\mathrm{r}=0.71)$. In addition to the checklist, demographic information of the participants was obtained. The information consisted of participants' age, job experience, education, working shifts, and the ward they worked in. The study was approved by the Ethical Committee of the Health Research Center of Baqiyatallah University of Medical Sciences, issued on 08/02/2011. Student's t-test was used to compare the quantitative variables. The chi-square test was used to compare the relationship between the qualitative and descriptive variables. The probability value of 0.05 or less $(P \leq 0.05)$ was set to know the significance level. The data were analyzed using the SPSS v. 18 (SPSS Inc., Chicago, Ill, USA).

\section{Results}

Of all participants, 127 (90.7\%) were female and 13 (9.3\%) were male. In terms of the level of education, 23 (16.4\%) held undergraduate diploma degrees, 68 (48.6\%) had Bachelor of Art (B.A.), 49 (35\%) had Master of Art (M.A.) or were physicians. Considering working shifts, 66 (50.8\%) were on morning shifts, eight $(6.2 \%)$ were on morning and evening shifts, and 56 (43.1\%) were on evening and night shifts. Table 1 and Figure 1 indicate HWC rates in the five domains included in the check list. Based on the Table 1, of all the observed cases, 115 (1.82\%) and 93 (3.72\%) washed their hands before leaving the ward and after performing a procedure, respectively. Tables 2 and 3 show the relationship between the measured variables and the five indexes of hand washing practice (i.e. items included in the checklist). According to the tables, males did more hand washing than females when entering the ward ( $P$ $=0.001)$. Also, the tables show that in comparison with diploma and M.A. holders , and physicians, B.A. holders did more hand washing after touching documents, telephones, etc., before and after performing a procedure, and before leaving the ward $(\mathrm{P}=0.001)$. Moreover, it was found that those on the evening and night shifts performed the practice more than those in the morning and evening shifts. According to the obtained results, there was no significant relationship between hand washing practice when entering the ward and the variables of age $(P=0.641)$, job experience $(P=0.052)$, and the number of patients and personnel on a working shift $(\mathrm{P}=0.185)$. Additionally, there was a positive relationship between hand-washing and job experience when it came to washing hands after touching documents, telephones, etc. (P $=0.031$ ). That is more job experience was associated with more hand-washing practices. There was no significant relationship between washing hands before performing a procedure and the variables of age, job experience, and the number of patients and personnel on a working shift $(\mathrm{P}=0.001)$.

Table 1. Hand-Washing Compliance Rates for the Five Studied Domains

\begin{tabular}{lc}
\hline & $\begin{array}{c}\text { Hand-Washing Compli- } \\
\text { ance Rates, No. (\%) }\end{array}$ \\
\hline When entering the ward & $23(17.2)$ \\
$\begin{array}{l}\text { After touching documents, tele- } \\
\text { phones, etc. }\end{array}$ & $37(28)$ \\
Before performing a procedure & $45(35.4)$ \\
After performing a procedure & $94(72.3)$ \\
Before leaving the ward & $115(82.1)$ \\
Total & $199(36)$ \\
\hline
\end{tabular}

\begin{tabular}{|c|c|c|c|c|c|}
\hline Variable & $\begin{array}{c}\text { When Entering } \\
\text { the Ward }\end{array}$ & $\begin{array}{l}\text { After Touching } \\
\text { Documents }\end{array}$ & $\begin{array}{l}\text { Before Performing } \\
\text { a Procedure }\end{array}$ & $\begin{array}{c}\text { After Performing a } \\
\text { Procedure }\end{array}$ & $\begin{array}{c}\text { Before Leaving } \\
\text { the Ward }\end{array}$ \\
\hline \multicolumn{6}{|l|}{ Gender } \\
\hline Male & 3.58 & 7.41 & 1.23 & 8.53 & 9.76 \\
\hline Female & 1.13 & 7.26 & 8.36 & 4.74 & 7.82 \\
\hline Pvalue & 0.001 & 0.316 & 0.379 & 0.187 & 0.703 \\
\hline \multicolumn{6}{|l|}{ Education } \\
\hline Diploma & 13 & 19 & 3.31 & 3.81 & 7.95 \\
\hline Bachelor & 4.22 & 1.39 & 7.5 & 5.95 & 100 \\
\hline Master of science and physician & 4.11 & 17 & 6.13 & 2.36 & 51 \\
\hline Pvalue & 0.272 & 0.23 & 0.001 & 0.001 & 0.001 \\
\hline \multicolumn{6}{|l|}{ Working shift } \\
\hline Morning & 8.14 & 9.33 & 5.31 & 9.71 & 9.87 \\
\hline Morning and evening & 0 & 0 & 0 & 5.12 & 5.37 \\
\hline Evening and night & 6.23 & 8.3 & 1.49 & 5.87 & 9.92 \\
\hline Pvalue & 0.182 & 0.145 & 0.012 & 0.001 & 0.001 \\
\hline
\end{tabular}

\footnotetext{
a All numbers are presented as $\%$.
} 
Gholami Fesharaki M et al.

\begin{tabular}{|c|c|c|c|}
\hline Levels & Age, Mean, y & Job experience, Mean, y & Number of patients, Mean \\
\hline \multicolumn{4}{|c|}{ When entering the ward } \\
\hline No & 50.35 & 66.9 & 44.11 \\
\hline Yes & 13.36 & 36.12 & 70.21 \\
\hline Pvalue & 0.641 & 0.052 & 0.185 \\
\hline \multicolumn{4}{|c|}{ After touching documents, telephones, etc. } \\
\hline No & 30.35 & 41.9 & 66.12 \\
\hline Yes & 97.36 & 31.12 & 81.12 \\
\hline Pvalue & 0.308 & 0.031 & 0.747 \\
\hline \multicolumn{4}{|c|}{ Before performing a procedure } \\
\hline No & 56.36 & 90.9 & 95.12 \\
\hline Yes & 98.33 & 95.9 & 56.13 \\
\hline Pvalue & 0.07 & 0.865 & 0.615 \\
\hline \multicolumn{4}{|c|}{ After performing a procedure } \\
\hline No & 81.37 & 39.1 & 25.8 \\
\hline Yes & 7.34 & 72.9 & 56.14 \\
\hline Pvalue & 0.055 & 0.684 & 0.004 \\
\hline \multicolumn{4}{|c|}{ Before leaving the ward } \\
\hline No & 20.38 & 20.11 & 72.7 \\
\hline Yes & 28.35 & 97.9 & 79.13 \\
\hline Pvalue & 0.083 & 0.438 & 0.003 \\
\hline
\end{tabular}

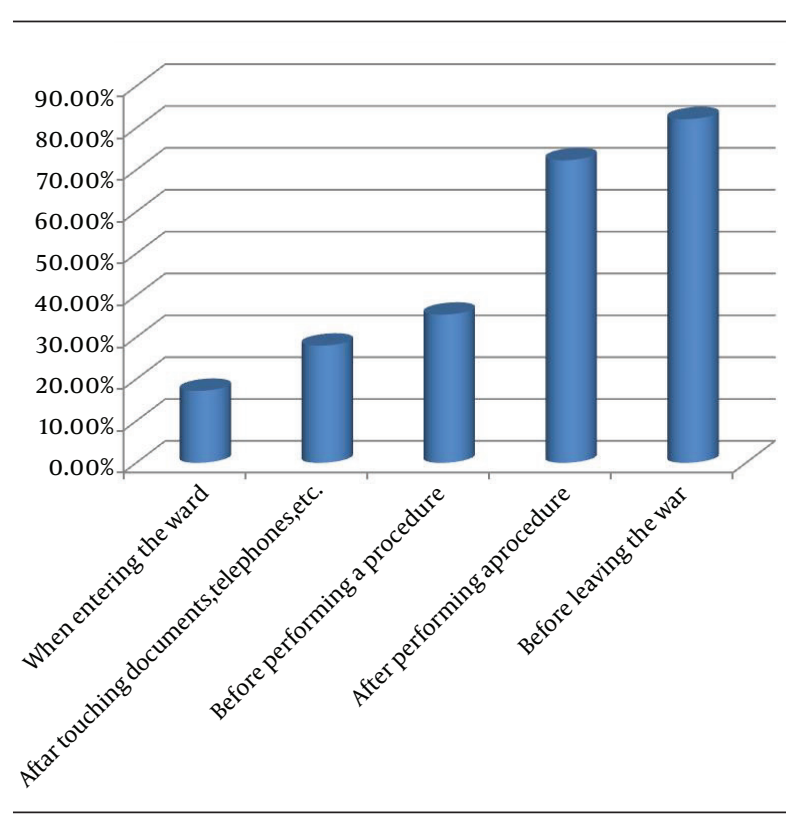

Figure 1. Hand-Washing Compliance Rate for the Five Studied Domains

\section{Discussion}

The simplest and the most effective way to prevent infection transmission is hand-washing. As a result of contacts between patients, physicians, and nurses, microbes can be easily transmitted through contaminated hands.
Therefore, correct hand-washing practice is necessary for all patients and hospital staff (14). According to the findings of the current study, $36 \%$ of the participants observed HWC. After coming into contact with patients, the number reduced to $3.72 \%$. In the study conducted by Jouybari et al. HWC rate was reported to be $61.1 \%$, after coming into contact with patients (15). In the current study and the study by Naghili et al. the number was $3.72 \%$ and $6.56 \%$, respectively (16). One systematic review study indicated that universal HWC rates were low and that they vary quantitatively depending on situational factors (17). The results of the current study showed that in most cases, care staff washed their hands before leaving the ward and after performing a procedure, suggesting that the care staff do mind the health of themselves and their families. On the other hand, when entering the ward, after touching documents, telephones, etc., and before performing a procedure which are directly related to the health of patients, they did not pay much attention to HWC, implying that patients' health and transferring hospital-acquired infections to them is not a major concern for the evaluated care staff. Also, the findings of the present study indicated that males did more hand-washing than females when entering the ward and in comparison with diploma, M.A. holders, and physicians, B.A. holders washed their hands more often after touching documents, telephones, etc. before and after performing a procedure, and before leaving the ward. Thus, the need for a training program is felt. The study conducted by 
Nazari et al. indicated that nursing students performed weaker than the employed nurses and both groups were in need of receiving in-service training regarding preventing and controlling hospital-acquired infections (5). The results of another study showed that using soap and water and having a training program could decrease hospital-acquired infections significantly (16). In terms of washing hands before and after performing a procedure and before leaving the ward, more occurrence of the practice was observed among the care staff in the evening and night working shifts. From this perspective, the current study findings were similar to those reported by Alsubaie et al. (18). According to their study, when entering wards, females do the hand washing practice less than males. The opposite was reported in earlier studies (19). The disagreement can be tentatively accounted for the idea that Iranian women, in comparison with men, conceive their hands as to be naturally cleaner. There was no statistically significant relationship between the HWC rate obtained for ward-entering cases and the variables of age and the number of patients and personnel on a working shift. Parallel to the increase in the job experience of care staff, there was an increase in the HWC rate after touching documents, telephones, etc. No significant relationship was observed between before-the-procedure HWC rate and the variables of age, job experience, and the number of patients and personnel on a working shift.

\subsection{Limitation}

Researchers' observation may affect the personnel's performance, which might be also the case in the current study.

\subsection{Conclusions}

In view of the current study findings, and the low rate of HWC, especially when entering wards and coming into contact with patients, it is suggested that a long-term and continuous training program be planned and implemented in order to improve HWC according to the model proposed by Marra et al. (3).

\section{Acknowledgements}

The authors would like to acknowledge their gratitude to the participants of the current study for their cooperation.

\section{Authors' Contributions}

Mohammad Gholami Fesharaki, Zohreh Aghamiri and Masome Mohamadian developed the original idea and collected the data. Fatemeh Rahmati-Najarkolaei and Mohammad Gholami Fesharaki prepared and edited the manuscript.

\section{Funding/Support}

The study was financially supported by Najmieh Hospital in Baqiyatallah University of Medical Sciences, Tehran, Iran.

\section{References}

1. Weinstein RA. Infection control in hospital.New York: McGraw-Hill; 2001.

2. Burke JP. Infection control - a problem for patient safety. $N$ Engl J Med. 2003;348(7):651-6.

3. Marra AR, Noritomi DT, Westheimer Cavalcante AJ, Sampaio Camargo TZ, Bortoleto RP, Durao Junior MS, et al. A multicenter study using positive deviance for improving hand hygiene compliance. Am J Infect Control. 2013;41(11):984-8.

4. Ray SK, Amarchand R, Srikanth J, Majumdar KK. A study on prevalence of bacteria in the hands of children and their perception on hand washing in two schools of Bangalore and Kolkata. Indian J Public Health. 2011;55(4):293-7.

5. Nazari R, Saberi M, Khazaie Nezhad S. [Comparison of Nurses and Nursing Students' Knowledge and Practice about Prevention and Control of Nosocomial Infection]. J Dev Res Nurs Midwifery. 2012;9(1):76-83.

6. Pitted D, Harbarth SG. The intensive care unit.Philadelphia: Lippincott Raven; 1998.

7. Edmond MB, Wenzel RP. Isolation. Mandel, Douglas \& Bennett's principle and practice of infectious disease.Philadelphia: Churchill Livingston; 2000.

8. Kampf G, Loffler H, Gastmeier P. Hand hygiene for the prevention of nosocomial infections. Dtsch Arztebl Int. 2009;106(40):649-55.

9. Allegranzi B, Pittet D. Role of hand hygiene in healthcare-associated infection prevention.J Hosp Infect. 2009;73(4):305-15.

10. Steere AC. Handwashing Practices for the Prevention of Nosocomial Infections. Anna Int Med. 1975;83(5):683.

11. Helder OK, van Goudoever JB, Hop WC, Brug J, Kornelisse RF. Hand disinfection in a neonatal intensive care unit: continuous electronic monitoring over a one-year period. BMC Infect Dis. 2012;12:248.

12. Takahashi I, Osaki Y, Okamoto M, Tahara A, Kishimoto T. The current status of hand washing and glove use among care staff in Japan: its association with the education, knowledge, and attitudes of staff, and infection control by facilities. Environ Health Prev Med. 2009;14(6):336-44.

13. Fridkin SK, Welbel SF, Weinstein RA. Magnitude and Prevention of Nosocomial Infections in the Intensive Care Unit. Infec Disease Clin North Americ. 1997;11(2):479-96.

14. Savolainen-Kopra C, Haapakoski J, Peltola PA, Ziegler T, Korpela T, Anttila P, et al. Hand washing with soap and water together with behavioural recommendations prevents infections in common work environment: an open cluster-randomized trial. Trials. 2012;13:10.

15. Jouybari L, Sanagoo A, Vakili A. Study of hand-washing of the staffs working in Gorgan educational hospitals, as well as the factors affecting on it. Gorgan Univ Med Sci Iran.1997.

16. Naghili B, Sadeghi H, Azami S, Valizade L, Heydarnejad H, Zamanzade V. [Performance of staff hand washing intensive teaching hospitals of Tabriz University of Medical Sciences].Tabriz, Iran: First Congress of Clinic Governance Cont Qual Improvement; 2012.

17. Erasmus V, Daha TJ, Brug H, Richardus JH, Behrendt MD, Vos MC et al. Systematic review of studies on compliance with hand hygiene guidelines in hospital care. Infect Control Hosp Epidemiol. 2010;31(3):283-94.

18. Alsubaie S, Maither A, Alalmaei W, Al-Shammari AD, Tashkandi M, Somily AM, et al. Determinants of hand hygiene noncompliance in intensive care units. Am J Infect Control. 2013;41(2):131-5.

19. Szilagyi L, Haidegger T, Lehotsky A, Nagy M, Csonka EA, Sun X, et al. A large-scale assessment of hand hygiene quality and the effectiveness of the "WHO 6-steps". BMC Infect Dis. 2013;13:249. 